\title{
Improved Carbon Dioxide Capture Using Nanostructured Ceramic Membranes
}

\author{
Ngozi Claribelle Nwogu, Edward Gobina, Mohammed Nasir Kajama \\ Centre for Process Integration and Membrane Technology, School of Engineering, Robert Gordon University, Aberdeen, UK. \\ Email: n.c.nwogu@rgu.ac.uk, e.gobina@rgu.ac.uk,m.n.kajama@rgu.ac.uk
}

Received August $8^{\text {th }}, 2013$; revised September $5^{\text {th }}, 2013$; accepted September $13^{\text {th }}, 2013$

Copyright (C) 2013 Ngozi Claribelle Nwogu et al. This is an open access article distributed under the Creative Commons Attribution License, which permits unrestricted use, distribution, and reproduction in any medium, provided the original work is properly cited.

\begin{abstract}
A nanoporous-structured tubular hybrid inorganic membrane capable of stripping carbon dioxide from flue gas stream was designed and tested at laboratory scale to improve compliance with various environmental regulations to cushion the effect of global warming. Single gas separation experiments using silica modified ceramic membrane were carried out to investigate individual gas permeation behaviors at different pressures and membrane efficiency after a dip coating method. Four gases: Nitrogen $\left(\mathrm{N}_{2}\right)$, Carbon dioxide $\left(\mathrm{CO}_{2}\right)$, Oxygen $\left(\mathrm{O}_{2}\right)$ and Methane $\left(\mathrm{CH}_{4}\right)$ were used. Plots of flow rate versus pressure were generated. Results show that the gas flow rate increases with pressure drop. However at above a pressure of 4 bars, the flow rate of $\mathrm{CO}_{2}$ was much higher than the other gases, indicating dominance of a more selective absorptive type transport mechanism.
\end{abstract}

Keywords: Ceramic Membrane; Carbon Dioxide Capture; Permeability; Selectivity; Gas Transport Mechanisms

\section{Introduction}

About one third of the overall $\mathrm{CO}_{2}$ emission globally comes from energy creation. Its decrease and management are vitally critical and they are important factors to ease global warming [1]. The position of $\mathrm{CO}_{2}$ in global warming is a present-day ecological concern and needs urgent attention in the provision of technologies that will curtail the emission of $\mathrm{CO}_{2}$ [2]. $\mathrm{CO}_{2}$ removal from flue gas stream recorded the success with conventional technology like absorption using glycol, amine and methanol under low temperature, the process with hot potassium carbonate, the reaction with calcium oxide and the use of polymer membrane. These processes employ low temperature resulting in energy losses due to high temperature recuperation as well as cooling of the gas stream [3]. Owing to the burning desire to abate global warming especially at the rate of $\mathrm{CO}_{2}$ emission and its concentration in the atmosphere through flue gases today, inorganic ceramic membrane with distinct characteristics should be a key issue. Cost effective, energy-saving, high chemical resistance, cheap materials are needed in the development of membrane module for manufacturing purposes. Porous inorganic membrane conquers some rather than all of the in-built limitations. They can tolerate higher temperature and basically limit the connection between selectivity and permeability. If properly designing the pore size and its distribution decides its selectivity while the volume fraction porosity regulates and establishes permeability [3]. Porous inorganic membrane also shows exceptional evidence of physical and chemical properties, including unresponsiveness to sarcastic environment, stability under high temperature, homogeneous pore structure and reasonable fluxes [4]. Some membranes today have been used for decades in $\mathrm{CO}_{2}$ capture, but, because the membrane is used for natural gas at very high pressure, they are unsuitable for $\mathrm{CO}_{2}$ capture from flue gases. Design and fabrication of porous ceramic membrane consist of several layers of different materials namely: Aluminium oxide $\left(\mathrm{Al}_{2} \mathrm{O}_{3}\right)$, Titanium Oxide $\left(\mathrm{TiO}_{2}\right)$, Zirconium Oxide $\left(\mathrm{ZrO}_{2}\right)$, Silicon dioxide $\left(\mathrm{SiO}_{2}\right)$, Silicon carbide, Zeolite or a mixture of two materials applied on an underlying porous stainless steel, $\alpha$ alumina, $\gamma$-alumina, zirconium, zeolite supports [5]. The manner in which gas molecules flow across the membrane referred to permeation mechanism is a significant fact in membrane technology. This flow is generally influenced by three factors: the gas properties, morphology of the membrane and the material used for membrane design. Consequently a hybrid material made from ceramics membrane has been well thought out by means of Nanotechnology. The technology is eco-friendly, eco- 
nomical and very efficient. It's applicable in all forms of $\mathrm{CO}_{2}$ elimination from other gases and its effectiveness increases comparatively to the $\mathrm{CO}_{2}$ concentration in the flue gas stream feed. Nanotechnology is among the ranges of technologies paying attention to exploring the carboncapturing technology [6]. Membrane separation of gases is a highly complex process and therefore the material used for its preparation should exhibit a long-lasting characteristic, stability and modify in an advanced manner to be adapted to separate specific gases.

However, the innovation is that a so called agent is immobilized in the membrane porous network, thus assisting to attract the $\mathrm{CO}_{2}$, and enhancing its transport across the membrane. This is in complete contrast to the more common and older method of using a filter that separates directly between $\mathrm{CO}_{2}$ and other gases.

\section{Experimental}

The gas separation experiment was performed using a membrane support and a nano-structured membrane deposited on a macro porous tubular filter employing a repeat dip-coating technique [6]. The gases used for the gas transport tests included Nitrogen $\left(\mathrm{N}_{2}\right)$, Carbon dioxide $\left(\mathrm{CO}_{2}\right)$, Oxygen $\left(\mathrm{O}_{2}\right)$ and Methane $\left(\mathrm{CH}_{4}\right)$ respectively.

The experiment was carried out to investigate the single gas permeation behaviors of the gases listed above with the permeation done separately and individually.

In Figure 1, the picture at the top is a tubular ceramic support before modification while the one at the bottom is the nano-structured composite which was modified after a dip coating technique.

Figure 2 shows the permeation cell set up. The components of the cell includes: 1) Gas cylinder, 2) pressure valve, 3) pressure guage, 4) membrane reactor, 5) retentate, 6) permeate and 7) flow meter respectively.

\section{Morphology of Support}

The scanning electron microscopy was used to verify the morphology of the support. The image is shown in Figures 3 and 4 respectively.

\section{Applicable Theory}

The manner in which gas molecules flow across composite membrane comprising of the membrane and the support with respect to the pressure will be determined. In addition, a distinction between viscous and Knudsen flow mechanisms in porous membrane to determine flaws in the membrane before and after coating will be illustrated. A schematic illustration of the transport porous is shown in Figure 5 involving interactions between gas molecules and pore surface to determine flows in the membrane before and after coating will be illustrated. A schematic illustration of the transport process is

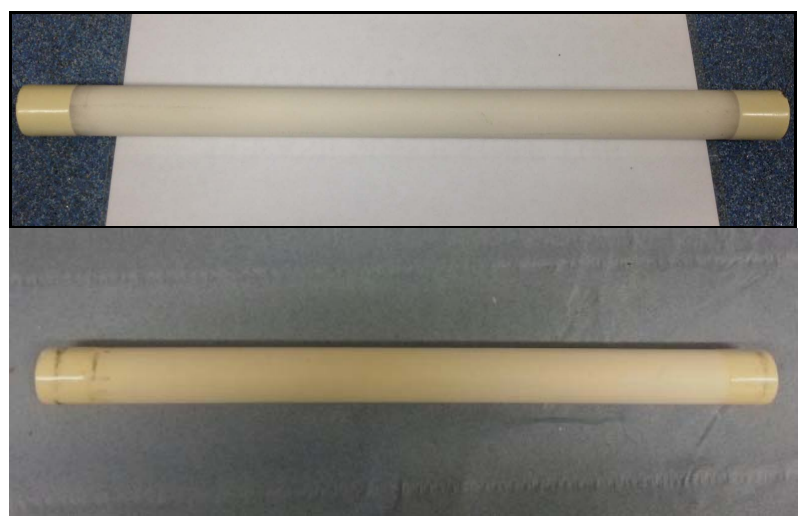

Figure 1. Tubular ceramic support (top) and nano-structured composite (bottom).

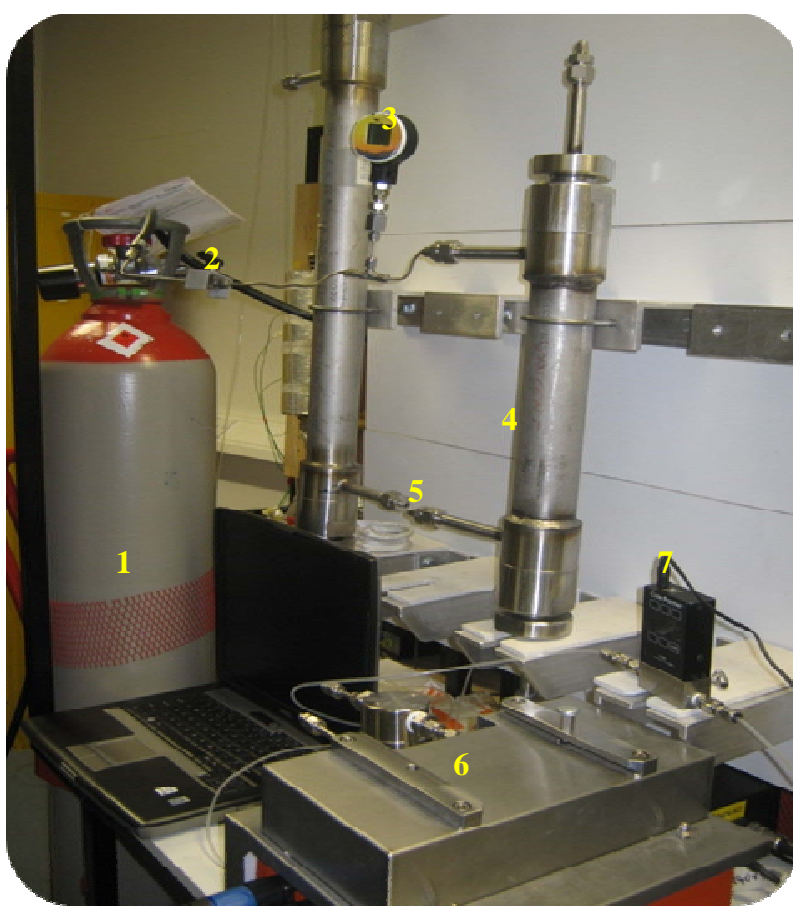

Figure 2. Permeation cell.

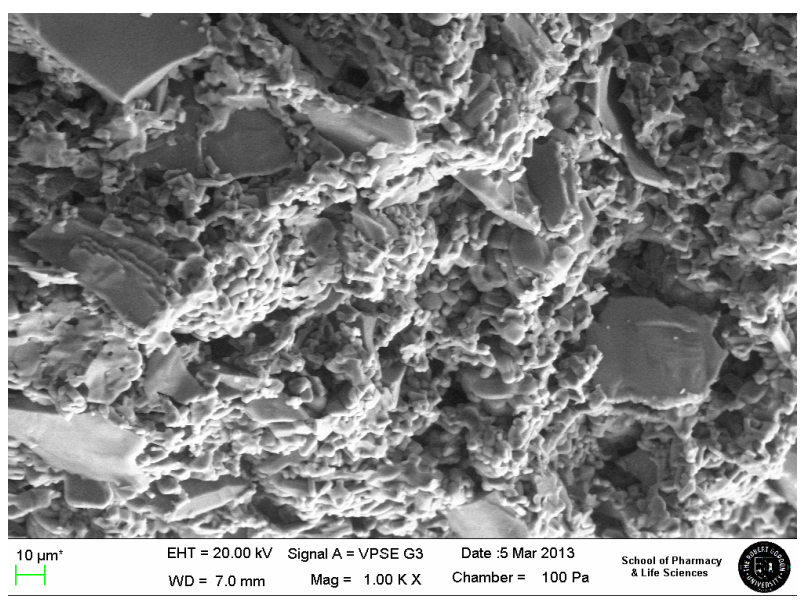

Figure 3. SEM membrane cross-section. 


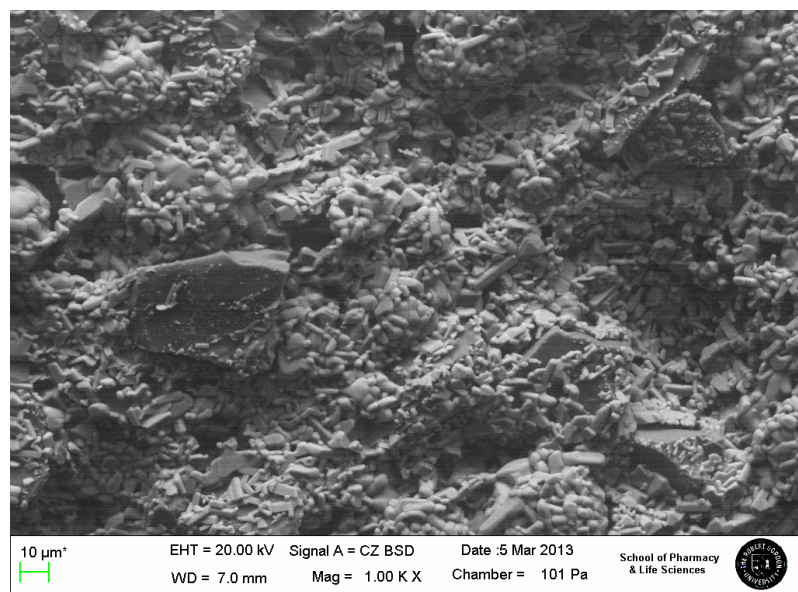

Figure 4. SEM membrane inner surface.

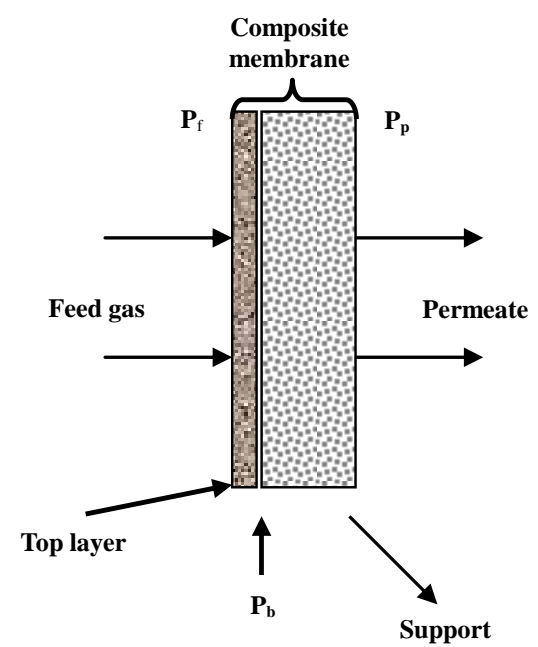

Figure 5. Schematic diagram of gas transport through a coated support membrane.

shown in Figure 5.

Values of gas permeation rate of the top layer from Figure 5 were calculated using the formula [7]

$$
J_{T L}=\frac{F}{\left(P_{f}-P_{b}\right) \times S}
$$

where $F(\mathrm{l} / \mathrm{min})$ is the flow rate through the membrane and $S\left(\mathrm{~m}^{2}\right)$ is the membrane surface area of the flow pathway $P_{f}$ (bar) and $P_{b}$ (bar) are absolute feed pressure and borderline pressure between the support and the toplayer. $P_{b}$ can be calculated from Equation (2) below

$$
P_{b}=\frac{-C_{\text {sup }}+\sqrt{C_{\text {sup }}^{2}+2 D_{\text {sup }}\left(C_{\text {sup }} P_{p}+\frac{1}{2} D_{\text {sup }} P_{p}^{2}+Z\right)}}{D_{\text {sup }}}
$$

where $C$ and $D$ are constants relative to membrane support characteristics and $Z$ given below for gas permeation through the composite membrane.

$$
Z=\left[C_{m}+\frac{1}{2} D_{m} \times\left(P_{f}+P_{p}\right)\right] \times P_{f}-P_{p}
$$

\section{Results and Discussion}

Accordingly, Figure 6 presents a plot of flow rate against pressure and the trend explains the proportionality for both parameters.

Figure 7 shows the plots of the ratio of flow rate of $\mathrm{CO}_{2}$ to that of $\mathrm{N}_{2}$ in relationship to the ratio of the molecular weight of $\mathrm{CO}_{2}$ to that of $\mathrm{N}_{2}$. The trend confirms that at pressure of 2 bar and above more $\mathrm{CO}_{2}$ was obtained from the separation.

Figure 8 also demonstrated that at pressure of 3 bars and above more of $\mathrm{CO}_{2}$ was separated from $\mathrm{O}_{2}$ while Figure 9 illustrates that from 2.4 bars and above more $\mathrm{CO}_{2}$ will be removed from $\mathrm{CH}_{4}$.

Figure 10 shows that gas flow through the support (sup) increased as the pressure was increased. For the

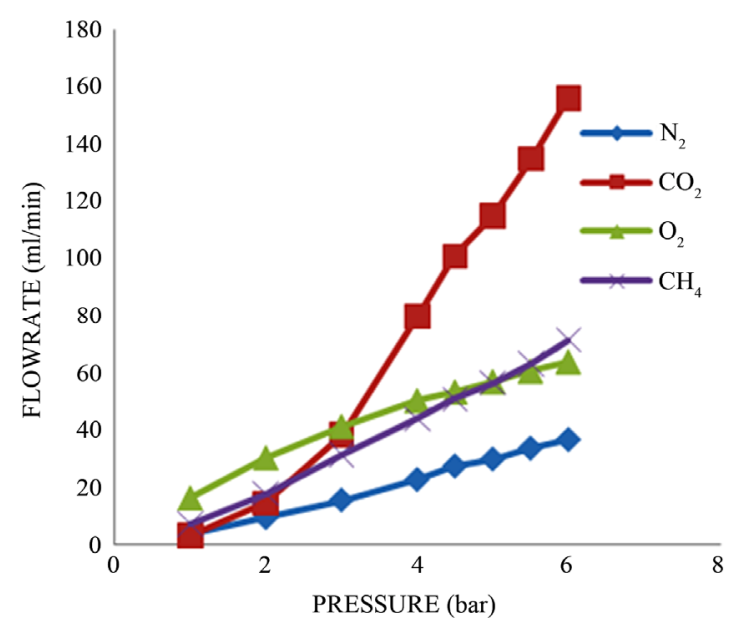

Figure 6. Graph of flow rate of $\mathrm{N}_{2}, \mathrm{CO}_{2}, \mathrm{O}_{2} \& \mathrm{CH}_{4}$ versus pressure.

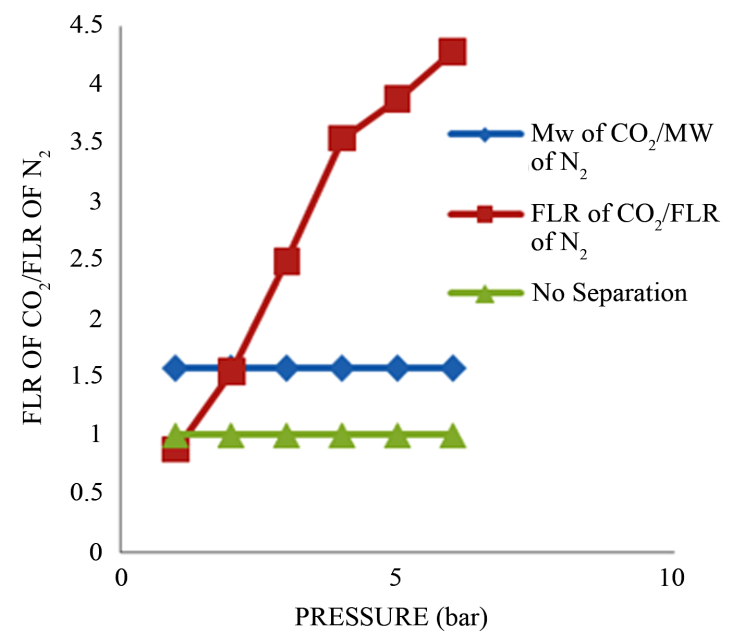

Figure 7. Ratio of flow rates and molecular weights of $\mathrm{CO}_{2}$ and $\mathrm{N}_{2}$ at different pressures. 


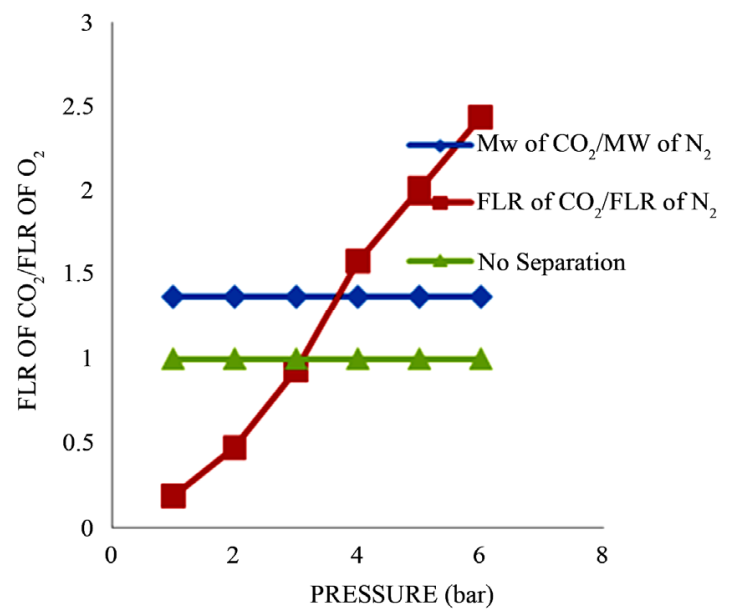

Figure 8. Ratio of flow rates and molecular weights of $\mathrm{CO}_{2}$ and $\mathrm{N}_{2}$ at different pressures.

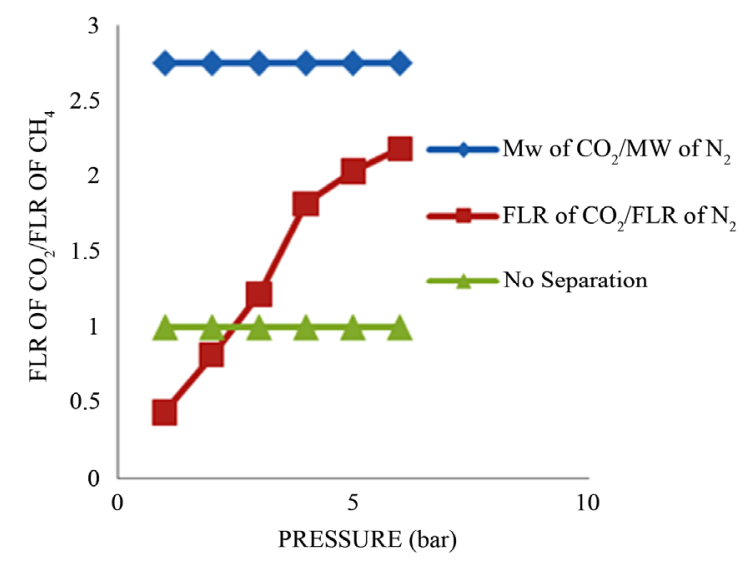

Figure 9. Ratio of flow rates and molecular weights of $\mathrm{CO}_{2}$ and $\mathrm{N}_{2}$ at different pressures.

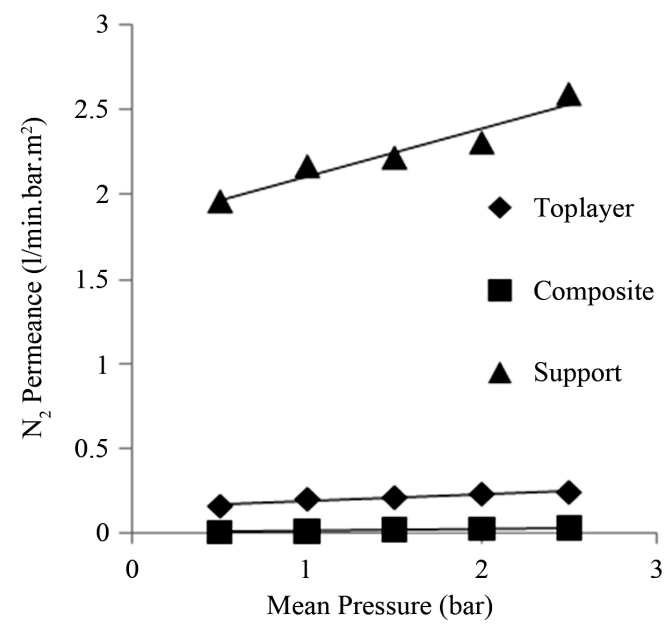

Figure 10. Membrane defect determination. top layer, the effect of pressure on the gas permeation was negligible even after a pressure build up.

As expected, the layer showed only minor dependence of permeance with average pressure suggesting the absence of defects.

\section{Conclusion}

Using the combination of Knudsen flow and viscous flow, it has been possible to extract the transport of the thin membrane layer in a composite hybrid system. For the support overall results have shown that both viscous and Knudsen flow can have a significant effect on the single gas transport. The dip coating technique had a significant effect toward achieving a zero level membrane deficiency. However, real flue gas will consist of mixtures and work is currently ongoing to obtain mixed gas transport and selectivity.

\section{REFERENCES}

[1] W. Yave, A. Car and K.-V. Peinemann, "Nanostructured Membrane Material Designed for Carbon Dioxide Separation,” Journal of Membrane Science, Vol. 350, No. 1-2, 2010, pp. 124-129. doi:10.1016/j.memsci.2009.12.019

[2] A. Meisen and X. Shuai, "Research and Development Issues in $\mathrm{CO}_{2}$ Capture," Energy Conversion and Management, Vol. 38, 1997, pp. S37-S41. doi:10.1016/S0196-8904(96)00242-7

[3] E. Gobina, "A Membrane Apparatus and Method Separating Gases,” US Patent 7297184 B2, 2006.

[4] B. A. McCool, N. Hill, J. DiCarlo and W. J. DeSisto, "Synthesis and Characterization of Mesoporous Silica Membranes via Dip-Coating and Hydrothermal Deposition Techniques," Journal of Membrane Science, Vol. 218, No. 1, 2003, pp. 55-67. doi:10.1016/S0376-7388(03)00136-4

[5] D. Shekhawat, D. R. Luebke and H. W. Pennline, "A Review of Carbon Dioxide Selective Membranes," US Department of Energy, NETL-1200, 2003, pp. 9-11.

[6] M. Karkare, "Nanotechnology: Fundamentals and Applications,” IK International Pvt Ltd., 2008, p. 12.

[7] A. W. Li, H. B. Zhao, J. H. Gu and G. X. Xiong, "Preparation of $\gamma-\mathrm{Al}_{2} \mathrm{O}_{3}$ Composite Membrane and Examination of Membrane Defects,” Science in China Series B: Chemistry, Vol. 40, No. 1, 1997, pp. 31-36. 